\title{
Relação entre doses de calda bordalesa e de fosfito potássico na intensidade do míldio e na produtividade da videira cv. 'Goethe'
}

\author{
Relation between doses of Bordeaux mixture and phosphites potassium on the intensity of \\ Downy Mildew on grape cv. 'Goethe'
}

\author{
Luiz Augusto Martins Peruch ${ }^{*}$ Emílio Della Bruna $^{\mathrm{I}}$
}

\section{RESUMO}

O míldio da videira, é uma das principais doenças dessa cultura no Sul do Brasil e provoca grandes perdas caso não sejam adotadas medidas de controle. Trabalhos envolvendo diferentes aspectos do patossistema são importantes para redução das perdas provocadas pela doença. O objetivo deste trabalho foi avaliar a influência de doses da calda bordalesa e do fosfito potássico no controle do míldio e na produtividade da videira cv. "Goethe" sob condições do Litoral Sul Catarinense, Brasil. Foram testadas as concentrações de 0,0,0,1, 0,2, 0,4 e 0,8\% do fungicida e do adubo foliar em um esquema fatorial de blocos ao acaso com três repetições. As variáveis de área abaixo da curva de progresso da doença (AACPD), porcentagem de cachos doentes (PCD) $e$ produtividade foram submetidas à análise de variância e de regressão. Diferenças para AACPD e PCD foram verificadas nas doses dos tratamentos. Por outro lado, não houve diferenças na comparação da calda bordalesa com fosfito, nem para as interações entre doses e tratamentos. Doses de $0,4 \%$ de calda bordalesa e $0,3 \%$ de fosfito controlaram a doença, pois reduziram em 98 e $94 \%$ a AACPD, bem como diminuíram em 46 e $76 \%$ a incidência nos cachos, respectivamente. Sintomas de fitotoxidez nas plantas foram observados nas doses de 0,8\% de calda bordalesa e 0,4\% de fosfito. Não foram verificadas diferenças de produtividade para nenhum dos fatores estudados. A calda bordalesa na dose de $0,4 \%$ e o fosfito potássico a $0,2 \%$ proporcionaram controle adequado do míldio na cv. 'Goethe'.

Palavras-chave: Plasmopara viticola, controle, fitotoxidez, produção.

\section{ABSTRACT}

The Downy Mildew, considered the most important disease of grape, causes great damage to the culture in the South of Brazil. News aspects of control, like new substances, should still be studied to reduce disease intensity. The objective of this research was to evaluate efficiency of Bordeaux mixture and phosphites on control of downy mildew and productivity of grape cv. 'Goethe' in the South Coastal of Santa Catarina, Brazil. The concentrations tested of $0.0 ; 0.1 ; 0.2 ; 0.4$ e $0.8 \%$ of the fungicide and the foliage fertilizer were evaluated in a $D B C$ factorial scheme with three repetitions. The AACPD, bunch diseased incidence (incidence) and productivity were submitted to regression analyses and $F$ test. Differences were observed for $A A C P D$ and incidence for concentrations, but not to different treatments and interactions between treatments and concentrations. The doses of $0.4 \%$ Bordeaux mixture and $0.3 \%$ phosphite reduced the AACPD in 98 and $94 \%$ and incidence in 46 and $76 \%$, respectively. Phytotoxycity symptoms were observed in $0.8 \%$ and $0.4 \%$ doses of Bordeaux mixture and phosphites, respectively. No differences were verified for productivity. The dosis of $0.4 \%$ of Bordeaux mixture and $0.3 \%$ of phosphites resulted in control of Downy Mildew of grape.

Key words: Plasmopara viticola, control, phytotoxicity, production

\section{INTRODUÇÃO}

O míldio, causado por Plasmopara viticola (Berk \& Kurt) Berlese \& de Toni, é uma das principais doenças da videira no Sul do Brasil (DALBÓ \& SCHUCK, 2003; SONEGO et al., 2002). Seus sintomas podem ser observados nas partes aéreas em desenvolvimento desde a primavera até o outono (GALLOTTI et al., 2004). Temperaturas entre $20-25^{\circ} \mathrm{Ce}$ umidade relativa de $95 \%$, bem como chuvas abundantes, são consideradas condições propícias ao desenvolvimento do míldio, sendo comum a ocorrência

'Laboratório de Fitopatologia, Empresa de Pesquisa Agropecuária e Extensão Rural de Santa Catarina S.A. Estação Experimental de Urussanga, CP 49, 88840-000, Urussanga, SC, Brasil. E-mail: lamperuch@epagri.rct-sc.br. *Autor para correspondência. 
de epidemias quando não são adotadas práticas de controle (GALLOTTI et al., 2004). Tais condições ocorrem freqüentemente durante o período vegetativo da cultura no Litoral Sul Catarinense, fazendo-se necessária a adoção de métodos de controle a fim de reduzir as perdas provocadas pela doença.

A pulverização de fungicidas e os tratos culturais e cultivares resistentes são alguns dos métodos de controle usualmente recomendados no manejo do míldio (AMORIM \& KUNIYUKI, 1997). Todavia, o método de controle aplicado com mais freqüência pelos produtores é a aplicação de fungicidas de contato e sistêmicos (SONEGO et al., 2005). Apesar de sua eficiência, a utilização de fungicidas, principalmente os sistêmicos, apresentam algumas restrições, tais como risco de seleção de populações resistentes do patógeno aos fungicidas e alto custo (BERGAMIM FILHO et al., 1995).

Atualmente, o processo produtivo agrícola sofre pressão da sociedade pela produção de alimentos de forma sustentável e sem resíduos (STADINIK \& TALAMINI, 2004). Por estas razões existe uma busca contínua por alternativas que sejam capazes de auxiliar no controle de doenças, mas que não representem risco ao homem e ao meio ambiente. Silicatos, ácidos cítricos e algas são alguns dos exemplos de substâncias com potencial de uso no controle de doenças (PERUCH \& SILVA, 2005; GALVÃO et al., 2006). Os fosfitos são, provavelmente, as substâncias de maior destaque. Apesar de serem considerados adubos, os fosfitos, devido a sua incompleta oxidação, apresentam maior solubilidade e absorção, bem como provocam efeitos únicos sobre o metabolismo das plantas (LOVATT \& MIKKELSEN, 2006). O fosfito de potássio é um sal de ácido fosforoso ligado ao potássio que apresenta a capacidade de estimular a planta para que esta forme substâncias de autodefesa, protegendo-a do ataque de fungos (SONEGO et al., 2005). Este tem sido utilizado no controle de várias doenças, em fruteiras de clima temperado (REUVENI et al., 2003; KATSURAYAMA \& BONETI, 2005; SONEGO et al., 2005), apesar de seu modo de ação não ter sido elucidado com exatidão (BONETI \& KATSURAYAMA, 2002). Alguns trabalhos demonstram que os fosfitos atuam diretamente sobre o fungo, enquanto outros afirmam que ocorre a ativação dos mecanismos de defesa das plantas (LOVATT \& MIKKELSEN, 2006). Neste caso, os fosfitos estimulariam a produção de fitoalexinas, substâncias naturais de defesa da planta, quando infectadas por algum patógeno. Os fosfitos têm sido aplicados com êxito no controle de míldio da videira (DALBÓ \& SCHUCK, 2003; GALVÃO et al., 2006), inclusive com resultados similares aos fungicidas (SONEGO et al., 2005).
Seguindo a tendência da aplicação de fungicidas menos tóxicos, destaca-se a calda bordalesa. Muitos trabalhos recomendam a utilização da calda bordalesa no controle do míldio da videira somente após a frutificação (AMORIM \& KUNIYUKI, 1997; GALLOTTI et al., 2004), mas não deixam claro se existem diferenças nas doses para as cultivares. Todavia, existe preocupação em relação à acumulação do cobre no solo e na planta com seu uso contínuo. Altas concentrações de cobre na planta podem ser extremamente tóxicas, causando sintomas como clorose, necrose, descoloração da folha e inibição de crescimento da raiz (YRUELA, 2005). Além disso, segundo BRUN et al. (2003), plantas ruderáceas têm seu desenvolvimento afetado por elevadas quantidades de cobre no solo.

Além dos aspectos relacionados ao fosfito e ao cobre, também deve ser considerada a cultivar em questão. No Brasil, a uva 'Goethe' é produzida exclusivamente no Litoral Sul Catarinense, sendo responsável por grande parte do vinho produzido na região. Todavia, apesar de sua importância econômica, não há pesquisas sobre vários aspectos desta cultivar. Em relação às doenças, a 'Goethe' é considerada medianamente susceptível ao míldio (MARIOTTI, 2003), motivo pelo qual se torna importante avaliar métodos alternativos de controle da doença.

O objetivo deste trabalho foi avaliar a relação das doses de calda bordalesa e de fosfito potássico no controle do míldio na folha e no cacho, bem como a sua influência na produtividade da cultivar 'Goethe'.

\section{MATERIAL E MÉTODOS}

O experimento foi desenvolvido na EMpresa de PesquisaAgropecuária e Extensão Rural de Santa Catarina (EPAGRI)/Estação Experimental de Urussanga, localizada no Litoral Sul Catarinense, situada geograficamente nas coordenadas S 28³1', O 49¹9' altitude: 48m, no período de setembro de 2002 a janeiro de 2003.

As doses e os produtos testados foram os seguintes: $0,0 \%, 0,1 \%, 0,2 \%, 0,4 \%$ e $0,8 \%$ de calda bordalesa e de fosfito potássico $\left(40 \% \mathrm{P}_{2} \mathrm{O}_{5}-20 \% \mathrm{~K}_{2} \mathrm{O}\right)$. No preparo da calda bordalesa foram diluídos separadamente o sulfato de cobre e a cal virgem em água. Em seguida, derramou-se a solução de cal sobre a de sulfato de cobre, medindo-se o pH com papel indicador. O fosfito potássico foi preparado pela mistura da água com o produto comercial, segundo as recomendações do fabricante. As pulverizações iniciaram-se quando a videira apresentou duas ou três folhas diferenciadas, estendendo-se até o início da compactação do cacho, sendo os tratamentos repetidos 
semanalmente. As pulverizações foram efetuadas com auxílio de um pulverizador costal com bico cone cheio com volume de calda variando de 1.200 a 1.850 litros ha $^{-1}$, conforme o estádio de desenvolvimento das plantas.

As parcelas foram compostas por quatro plantas adultas da cultivar "Goethe" com quinze anos de idade, conduzidas no sistema de latada num espaçamento $1,5 \times 3 \mathrm{~m}$, com densidade de 2.222 plantas $\mathrm{ha}^{-1}$. As plantas foram manejadas segundo sistema de produção da cultura (EPAGRI, 2005).

$\mathrm{O}$ efeito dos tratamentos sob o desenvolvimento do míldio foi avaliado nas folhas e nos cachos. As avaliações da doença na folha foram efetuadas em cinco ramos marcados aleatoriamente nas duas plantas centrais das parcelas. Para avaliação da severidade, foi utilizada uma escala diagramática com níveis variando de 0 a 100\% (AZEVEDO, 1997). No total foram realizadas seis avaliações em intervalos irregulares, dependendo do desenvolvimento do míldio. Com os dados de severidade foi determinada a área abaixo da curva de progresso da doença $(A A C P D)$, calculada pela expressão: $A A C P D=\Sigma\left(y_{i}+y_{i+1}\right) /\left(t_{i}+1-\right.$ $\mathrm{t}_{\mathrm{i}}$ ), em que $y_{\mathrm{i}}$ e $y_{\mathrm{i}+1}$ são os valores de severidade observados em duas avaliações consecutivas e t é o intervalo entre as avaliações (CAMPBELL \& MADDEN, 1990). A doença nos cachos foi quantificada na colheita pela determinação de sua porcentagem em todos os cachos, nas plantas da área útil das parcelas. Neste momento foi determinada a produtividade dos tratamentos por meio da pesagem dos cachos.

O experimento foi disposto em esquema fatorial 2x5 (dois produtos x cinco dosagens) num delineamento de blocos ao acaso com três repetições. Curvas de regressão em relação às doses da calda bordalesa e do fosfito potássico foram ajustadas aos dados de AACPD, incidência de cachos doentes e produção. A significância das regressões foi verificada pelo teste $\mathrm{F}$ a $5 \%$ de probabilidade de erro. As análises estatísticas foram efetuadas pelo programa SAEG (RIBEIRO JÚNIOR, 2001).

\section{RESULTADOS E DISCUSSÃO}

A análise estatística dos dados de AACPD determinou diferenças para o fator doses, mas não para o fator produtos e não houve interação significativa dos fatores doses $\mathrm{x}$ produtos (Tabela 1). A análise de regressão determinou que o aumento das doses da calda bordalesa e do fosfito potássico proporcionaram reduções dos valores de AACPD (Figuras 1a e 2a). Todavia, as doses de $0,8 \%$ de calda bordalesa e as de 0,4 e $0,8 \%$ de fosfito causaram sintomas de fitotoxidez, no início da brotação, nos cachos e nas folhas (dados
Tabela 1 - Valores de F calculados para calda bordalesa e fosfito (produtos), doses e interação entre os fatores para as variáveis área abaixo da curva de progresso da doença (AACPD), porcentagem de cachos doentes (\% cacho doente) e produtividade ( $\mathrm{kg}_{\text {parcela }}{ }^{-1}$ ) em videira $\mathrm{cv}$. 'Goethe' no Litoral Catarinense. EPAGRI/ EEUr, 2006.

\begin{tabular}{llcc}
\hline & \multicolumn{3}{c}{ Variáveis } \\
\hline Fatores & AACPD & $\begin{array}{c}\text { \% cacho } \\
\text { doente }\end{array}$ & Produtividade \\
Produtos & $0,04^{\mathrm{ns}}$ & $1,30^{\mathrm{ns}}$ & $1,09^{\mathrm{ns}}$ \\
Doses & $19,80^{* *}$ & $8,44^{* *}$ & $1,00^{\mathrm{ns}}$ \\
Interação produto x & $0,10^{\mathrm{ns}}$ & $0,46^{\mathrm{ns}}$ & $0,28^{\mathrm{ns}}$ \\
dose & & & \\
\hline
\end{tabular}

ns- não-significativo, * - significativo em nível de $5 \%$ de probabilidade e ** - significativo em nível de $1 \%$ de probabilidade pelo teste de F.

não demonstrados). Na avaliação da porcentagem de cachos doentes (PCD), foram verificadas diferenças para as doses de fosfito, mas não de calda bordalesa (Figuras 1b e 2b). A PCD foi menor com o aumento da dose de fosfito. Não foram verificadas diferenças nas análises entre os produtos e a interação entre produtos e doses (Tabela 1).

As doses de calda bordalesa geralmente recomendadas para controle do míldio na videira variam de $0,25 \%$ durante a formação do cacho a 0,25-0,5\% após a colheita (SONEGO et al., 2002; EPAGRI, 2005). Contudo, recomendações de doses de até $2 \%$ podem ser encontradas na literatura (AMORIM \& KUNIYUKI, 1997). Os resultados obtidos sugerem que doses de 0,4\% são suficientes no controle da doença devido à redução de $98 \%$ dos valores de AACPD (Figura 1a). Os dados de GALVÃO et al. (2006) corroboram estas afirmações, pois estes obtiveram uma redução de $50 \%$ da severidade do míldio com dose de 0,5\% no Litoral Catarinense. A preocupação de recomendar doses mais baixas, mas eficientes, reside no problema de acúmulo de cobre na planta e no solo. Todavia, os dados de produtividade não deixaram claros os possíveis efeitos negativos do cobre sobre as videiras, pois não foram verificadas diferenças entre as doses. Sabe-se que o excesso de cobre pode provocar uma série de distúrbios nas plantas, resultando em biomassa reduzida e sintomas cloróticos (YRUELA, 2005). Neste experimento, os resultados demonstraram controle eficiente da doença com dose de $0,4 \%$ de calda bordalesa.

Em relação ao fosfito potássico, analisandose a tendência da curva da regressão, pode-se afirmar que doses de $0,3 \%$ foram suficientes para reduzir em 94 e $76 \%$ a AACPD e a incidência do míldio no cacho, respectivamente (Figuras 2a e 2b). Resultados 


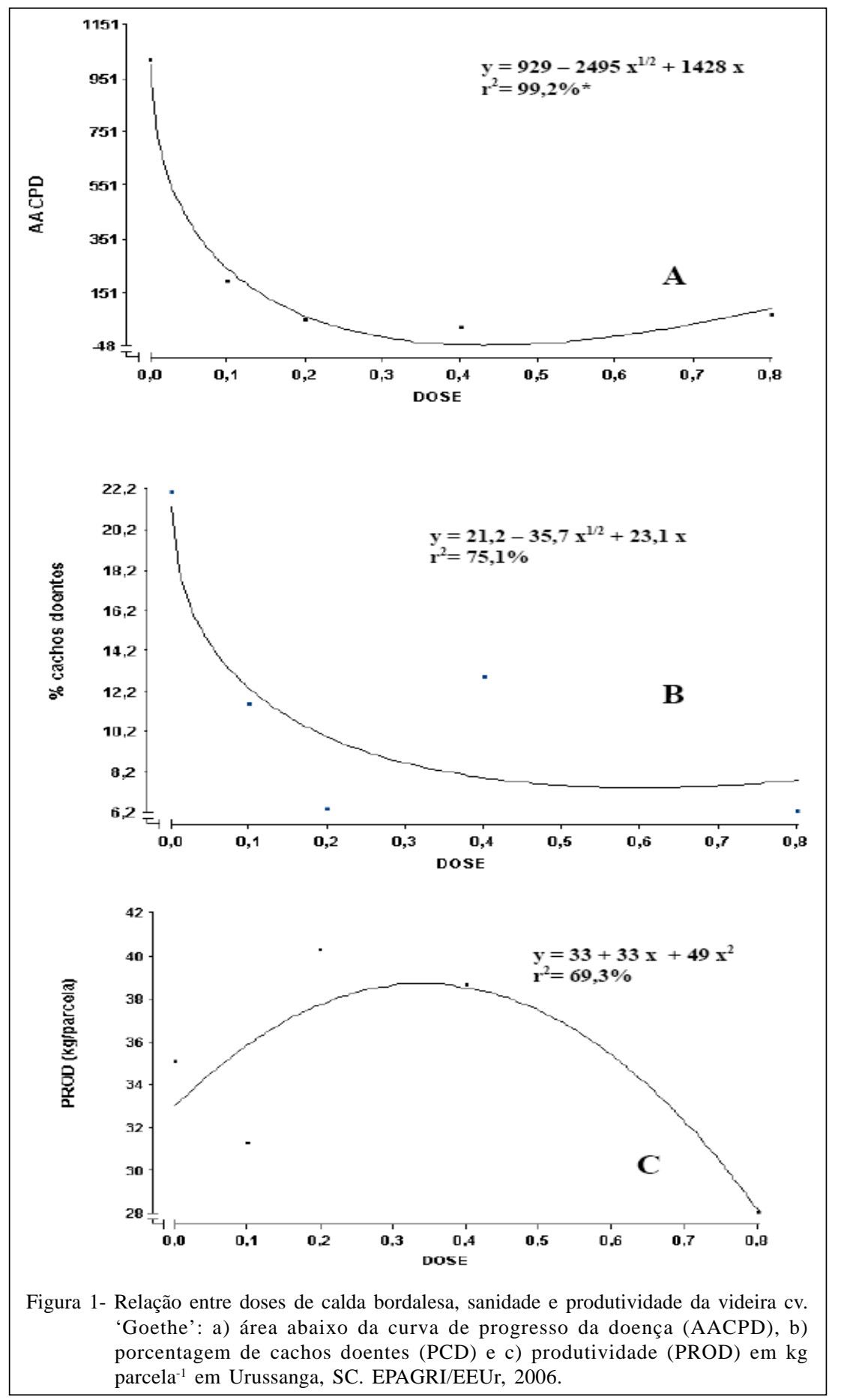

semelhantes foram obtidos em outras cultivares viníferas em diversos estudos (DALBÓ \& SCHUCK, 2003; SONEGO et al., 2005; GALVÃO et al., 2006). Segundo SONEGO et al. (2005), os fosfitos foram eficientes em ensaios de controle do míldio com Cabernet Sauvignon usados de forma preventiva. Já DALBÓ \& SCHUCK (2003) verificaram controle da doença com doses de 0,25-0,3\% na Cabernet Sauvignon, no Planalto Catarinense. Ambos os estudos reportaram níveis de controle igual ou superior aos fungicidas padrões pela aplicação de fosfitos. Ressalva deve ser feita em relação à fitotoxidez do fosfito potássico. Neste trabalho, foram observados sintomas de fitotoxidez a partir das doses de $0,4 \%$. Tal problema 


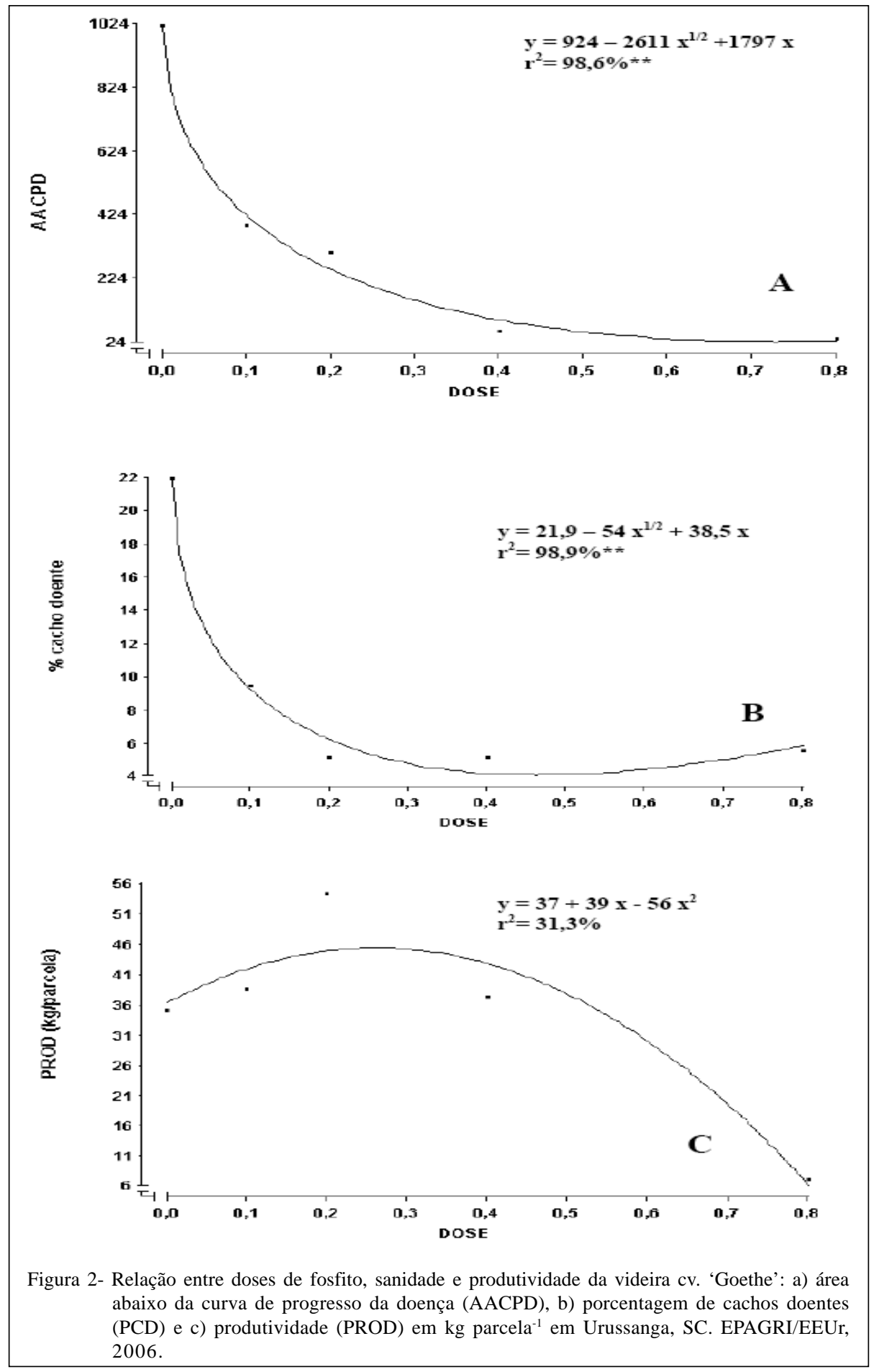

também foi verificado na Cabernet Sauvignon em doses de $0,3 \%$, especialmente nas aplicações feitas nas horas mais quentes do dia (DALBÓ \& SCHUCK, 2003). Os fosfitos vêm sendo apontados como excelentes produtos no controle de Oomycetes. Todavia, o efeito do fosfato pode ser baixo para algumas doenças foliares
(LOVATT \& MIKKELSEN, 2006), o que demonstra a necessidade de estudos em outros patossistemas.

Não foram verificadas diferenças na produtividade para os produtos e as doses, e também não houve a interação desses dois fatores (Tabela 1). Os modelos também não foram significativos para 
regressões, sendo que as taxas de correlação foram baixas para a calda bordalesa (69 \%) e o fosfito (31\%) (Figuras 1c e 2c). Parece haver uma influência do aumento da dose da calda bordalesa na questão da produtividade, segundo o que a curva apresenta (Figura 1c), mas isso não foi comprovado pelas análises estatísticas. Para esta variável é possível que os tratamentos tenham sido influenciados pelo potencial produtivo das plantas ou por outros aspectos que fugiram ao controle experimental. As mesmas pressuposições valem para as resultados verificados nas doses de fosfito (Figura 2c).

$\mathrm{O}$ aspecto produtivo nem sempre foi abordado nos trabalhos recentes com calda bordalesa e fosfitos em videira (DALBÓ \& SCHUCK, 2003; SONEGO et al., 2005; GALVÃO et al., 2006). Todavia, esperava-se um efeito positivo para doses de fosfito potássico, visto que o aumento da produtividade foi comprovado para laranja com apenas uma pulverização (LOVATT \& MIKKELSEN, 2006). Segundo os autores, aplicações com fosfito também aumentam a produtividade em culturas como o alho e a batata. O efeito de doses superiores na produtividade e na fitotoxidez são aspectos que devem ser estudados no futuro, pois se sabe que diferentes espécies e cultivares de plantas podem apresentar tolerâncias distintas a altas concentrações de metais (YRUELA, 2005).

\section{CONCLUSÕES}

Não existem diferenças de eficiência no controle do míldio entre a calda bordalesa e o fosfito, mas há diferenças somente nas suas doses. Considerando-se o controle da doença e a fitotoxidez nas plantas, determinou-se que as doses de $0,3 \%$ e $0,4 \%$ de fosfito e calda bordalesa foram as mais adequadas para o controle do míldio na cv. 'Goethe', respectivamente. Estudos mais aprofundados sobre a fitotoxidez devem ser realizados a fim de elucidar as doses críticas que não afetem a produtividade da cultura.

\section{REFERÊNCIAS}

AMORIM, L.; KUNIYUKI, H. Doenças da videira. In: KIMATI, H. (Ed.). Manual de fitopatologia: doenças das plantas cultivadas. São Paulo: Ceres, 1997. p.736-757.

AZEVEDO, L.A.S. Manual de quantificação de doenças de plantas. São Paulo: Novartis, 1997. 114p.

BERGAMIM FILHO, A. et al. Manual de fitopatologia. 3.ed. São Paulo: Ceres, 1995. V.1, 919p.

BONETI, J.I.S.; KATSURAYAMA, Y. Viabilidade do uso de fosfitos no manejo de doenças da macieira. In: ENFRUTE, 5. 2002, Fraiburgo, SC. Anais.... Florianópolis: EPAGRI, 2002. 271p. p.125-139.
BRUN, L.A. et al. Effects of elevated soil copper on phenology, growth and reproduction of five ruderal plant species. Environmental Pollution, Amherst, v.122, n.2, p.361-368, 2003

CAMPBELL, C.L.; MADDEN, L.V. Introduction to plant disease epidemiology. New York: John Willie \& Sons, 1990. $253 p$.

DALBÓ, M.A.; SCHUCK, E. Avaliação do uso de fosfitos para o controle do míldio da videira. Agropecuária Catarinense, Florianópolis, v.16, n.2, p.33-35, 2003.

EPAGRI. Normas técnicas para o cultivo da videira em Santa Catarina. Florianópolis: EPAGRI, 2005. N.33, 67p.

GALLOTTI, G.J.M. et al. Doenças da videira e seu controle em Santa Catarina. Florianópolis: EPAGRI, 2004. 90p. (Boletim técnico n. 51).

GALVÃO, S. et al. Avaliação de eficiência de produtos alternativos para o controle do míldio e da antracnose em videira, cultivar Niágara Branca. Agropecuária Catarinense, Florianópolis, v.19, n.4, p.91-93, 2006.

KATSURAYAMA, Y; BONETI, J.I.S. Avaliação do Fitofos cobre (fosfito de cobre) no controle de mancha da gala (Colletorichum sp.) em macieira, cv. Gala ciclo 04/05. In: ENFRUTE, 8., 2005, Fraiburgo, SC. Anais.... Florianópolis: EPAGRI, 2005. V.2. 271p. p.11.

LOVATT, C.J.; MIKKELSEN, R.L. Phosphite fertilizers: what are they? Can you use them? What can they do? Better Crops, Norcross, v.90, n.4, p.11-13, 2006.

MARIOTI, E.J. A uva Goethe, símbolo emblemático da vitivinicultura da região de Urussanga, SC. 2003. 35p. Capturado em 8 jan. 2007. On line. Disponível na internet: http://www.bu.ufsc.br/cac/uvagoethe.pdf.

PERUCH, L.A.M.; SILVA, A.C.F. Fungicidas alternativos para manejo da requeima do tomateiro. In: CONGRESSO BRASILEIRO DE AGROECOLOGIA, 3., 2005, Florianópolis, SC. Anais... Florianópolis: ABA/EPAGRI/UFSC, 2005. CD-ROM.

REUVENI, $M$ et al. Control of mold-core decay in apple fruits by $ß$ - aminobutiric acids and potassium phosphites. Plant Disease, Sta. Paul, v.87, n.8, p.933-936, 2003.

RIBEIRO JUNIOR, J.I. Análises estatísticas no SAEG. Viçosa: UFV, 2001. 301p.

SONEGO, O.R. et al. Avaliação do Fitophos K e Fitophos K plus (fosfito de potássio) no controle do míldio da videira. In: ENFRUTE, 8., 2005, Fraiburgo, SC. Anais.... Florianópolis: EPAGRI, 2005. V.2, 271p, p.12.

SONEGO, O.R. et al. Recomendações para o manejo das doenças fúngicas e das pragas da videira. Bento Gonçalves: EMBRAPA Uva e Vinho, 2002. 12p. (Circular técnica, 39).

STADNIK, M.J.; TALAMINI, V. Manejo ecológico de doenças de plantas. Florianópolis: CCA-UFSC, 2004. 293p.

YRUELA, I. Copper in plants. Brazilian Journal of Plant Physiology, Viçosa, v.17, n.2, p.145-156, 2005. 